\title{
Letters
}

Website: www.bmj.com

Email: letters@bmj.com

\section{New diagnostic criteria for diabetes mellitus}

New criteria result in fewer cases in older adults

EdITOR-The DECODE Study Group's paper on the implications of the American Diabetes Association's (ADA) recent changes in diagnostic criteria for diabetes mellitus raises several issues. ${ }^{1}$

The World Health Organisation's definition of diabetes that was used in the American report included both fasting glucose concentrations and concentrations 2 hours after a glucose load. ${ }^{2}$ In the DECODE paper, however, $\mathrm{WHO}$ criteria were defined by the glucose concentration after challenge alone. This difference in definition of the WHO criteria may help to explain why changes in prevalence estimates of diabetes presented in the DECODE paper differ from findings in the American report. A reanalysis of data using consistent definitions would be desirable.

More important questions stem from the DECODE Study Group's finding that the prevalence of diabetes in older adults will increase substantially with the ADA criteria. We believe that the opposite is likely to happen. Most people who have fasting glucose concentrations that are diagnostic of

\section{Advice to authors}

We prefer to receive all responses electronically, sent either directly to our website or to the editorial office as email or on a disk. Processing your letter will be delayed unless it arrives in an electronic form.

We are now posting all direct submissions to our website within 72 hours of receipt and our intention is to post all other electronic submissions there as well. All responses will be eligible for publication in the paper journal.

Responses should be under 400 words and relate to articles published in the preceding month. They should include $\leqslant 5$ references, in the Vancouver style, including one to the BMJ article to which they relate. We welcome illustrations.

Please supply each author's current appointment and full address, and a phone or fax number or email address for the corresponding author. We ask authors to declare any competing interest. Please send a stamped addressed envelope if you would like to know whether your letter has been accepted or rejected.

Letters will be edited and may be shortened.

www.bmj.com

letters@bmj.com diabetes will also have high glucose concentrations after a glucose load. However, glucose intolerance is a common feature of advancing age and often exists in subjects without a high fasting glucose concentration. As the ADA criteria emphasise fasting glucose concentration over glucose intolerance, fewer older people are likely to be classed as having diabetes overall. We therefore agree that the $\mathrm{ADA}$ criteria will potentially bias prevalence estimates of diabetes relevant to age, but these estimates will underestimate rather than overestimate the prevalence of diabetes in older adults.

The question of whether raised glucose concentrations after a glucose load in the absence of a raised fasting glucose concentration should be considered to be diabetes has been controversial. A recent study showed that isolated hyperglycaemia after challenge in women aged 50-89 with normal fasting glucose concentrations was associated with a 2.9-fold increase in risk of cardiovascular disease over 7 years of follow up. ${ }^{3}$ More prospective data in older populations are just becoming available and should be examined in terms of microvascular and macrovascular complications as part of the ongoing evaluation of the new criteria.

Helaine E Resnick Fellow

Tamara B Harris Chief, geriatric epidemiology Epidemiology, Demography and Biometry Program, National Institute on Aging, Gateway Building, Room 3C-309, Bethesda, MD 20892, USA

1 DECODE Study Group on behalf of the European Diabetes Epidemiology Study Group. Will new diagnostic D with diates? with diabetes? Reanalysis of Europe data. BMy 1998; $317: 371-5$. (8 August.)

2 Expert Committee on the Diagnosis and Classification of Elabe 1997;20:1183-97.

3 Barrett-Connor E, Ferrare A. Isolated postchallenge hyperglycemia and the risk of fatal cardiovascular disease in older women. The Rancho Bernardo study. Diabetes Car 1998;21:1236-9.

\section{Subjects with impaired glucose tolerance} but normal fasting values will not be identified

EDITOR-The paper by the DECODE Study Group and the accompanying editorial by Wareham and O'Rahilly on the new diagnostic criteria for diabetes highlighted the considerable reclassification of disease that would occur as a result of disagreement between the old and new classifications, as well as recommending that the diagnostic criteria should be changed only after analysis of prospective data. ${ }^{2}$ The new intermediate category of impaired fasting glucose concentra- tion $(6.1$ to $<7.0 \mathrm{mmol} / \mathrm{l})$ of the American Diabetes Association was mentioned in the editorial, ${ }^{2}$ but its effect on the intermediate group between normal and diabetic was not explored in the European data. ${ }^{1}$ The expert committee of the American Diabetes Association states that the new category of impaired fasting glucose concentration will not identify as many people with impaired glucose homoeostasis as the previous category of impaired glucose tolerance (glucose concentration 2 hours after a glucose tolerance test 7.8 to $<11.1 \mathrm{mmol} / \mathrm{l}){ }^{3}$. We are concerned that this group should not be forgotten because they are at risk of macrovascular complications. Results from the Paris prospective study show that the death rate from coronary heart disease in men aged 44-55 with a normal fasting plasma glucose concentration but impaired glucose tolerance was double that in subjects with normal glucose tolerance. ${ }^{4}$ Preventive measures could be usefully used in this group, yet it will not be identified under the new criteria.

The editorial and paper also did not discuss the effect that the new diagnostic criteria would have on people from different ethnic groups. ${ }^{12}$ Wide variations in the prevalence of diabetes and impaired glucose tolerance between different ethnic groups have been described, with standardised prevalence ratios for diabetes in comparison with white people of 2.7 (95\% confidence interval 1.8 to 4.0) in people of African descent and 3.8 (2.6 to 5.6) in those of South Asian origin. ${ }^{5}$ Further research is needed to investigate the effect of the new diagnostic criteria for diabetes on subjects from different ethnic groups and the implications for prevention and treatment.

Tess Harris Lecturer in general practice and primary care

tharris@sghms.ac.uk

Derek Cook Reader in epidemiology

Francesco P Cappuccio Senior lecturer in medicine Blood Pressure Unit, Department of Medicine, St George's Hospital Medical School, London SW17 0RE

1 DECODE Study Group on behalf of the European Diabetes Epidemiology Study Group. Will new diagnostic criteria for diabetes mellitus change phenotype of patients with diabetes? Reanalysis of European epidemito with diabetes? Reanalysis of Europe

anging classification and diagnosis of diabetes. BMJ 1998;317:359-60. (8 August.)

3 Expert Committee on the Diagnosis and Classification of Diabetes Mellitus. Report. Diabetes Care 1997;20:1183-97. 4 Charles MA, Balkau B, Vauzelle-Kervroedan F, Thibult N, Eschwege E. Revision of diagnostic criteria for diabetes. Lancet 1996;348:1657-8.

5 Cappuccio FP, Cook DG, Atkinson RW, Strazzullo P. Prevalence, detection and management of cardiovascular risk factors in different ethnic groups in south London. Heart 1997;78:555-63. 
Prevalence is reduced using these criteria rather than 1985 WHO criteria

EDITOR-The DECODE Study Group suggested that use of the diagnostic criteria of the American Diabetes Association (ADA) will lead to an increase in prevalence of diabetes. ${ }^{1}$ These data are consistent with those of Unwin et al, who showed that the ADA criteria resulted in an increase in prevalence in European, Chinese, and South Asian populations resident in the United Kingdom. ${ }^{2}$ In both studies subjects were classed as having diabetes on the basis of a fasting plasma glucose concentration of $\geqslant 7.0 \mathrm{mmol} / \mathrm{l}$ (ADA criterion) and on the basis of a glucose concentration 2 hours after a glucose load of $\geqslant 11.1 \mathrm{mmol} / \mathrm{l}$ alone (World Health Organisation criterion). In the past the WHO has recommended that only the 2 hour plasma glucose concentration be considered for epidemiological studies and diagnostic screening.

However, a WHO consultative document of 1985 states that for epidemiological studies "ideally both the 2 hour and fasting value should be used." Thus studies that have examined the impact of using the ADA criteria in comparison with using these WHO criteria (both the fasting and 2 hour glucose value) have shown a fall in the prevalence of diabetes..$^{3-5}$ In 2844 subjects aged 40-74 the prevalence of undiagnosed diabetes was $4.4 \%$ by $\mathrm{ADA}$ criteria and $6.4 \%$ by $\mathrm{WHO}$ criteria, a relative reduction of $31 \%{ }^{3}$ A similar approach in 2183 AsianIndian subjects showed a prevalence of $4.3 \%$ by ADA criteria and $5.2 \%$ by $1985 \mathrm{WHO}$ criteria, a relative reduction of $21 \%{ }^{4}$ Shaw et al looked at data from seven population based epidemiological surveys in the southern hemisphere of 15246 subjects. $^{5}$ The prevalence using WHO criteria was universally higher, ranging from $100 \%$ to $367 \%$ of that using ADA criteria.

The possibility of a reduced number of subjects with newly diagnosed diabetes is of concern, particularly when evidence suggests that type 2 diabetes should be identified at an early stage. The evidence so far suggests that application of the ADA criteria in comparison with using both the fasting and 2 hour glucose concentrations of the WHO criteria will reduce significantly the number of patients with newly diagnosed disease.

Reassuringly, the WHO consultative document retains the potential to use both fasting and 2 hour plasma glucose concentrations in routine clinical practice for the diagnosis of diabetes.

Melanie Davies Consultant physician

Department of Diabetes and Endocrinology,

Leicester Royal Infirmary, Leicester LE1 5WW

1 DECODE Study Group on behalf of the European Diabetes Epidemiology Study Group. Will new diagnostic criteria for diabetes mellitus change phenotype of patients with diabetes? Reanalysis of European epidemiological data. BMJ 1998;317:371-5. (8 August.)

2 Unwin N, Alberti KGMM, Bhopal R, Harland J, Watson W, White M. Comparison of the current WHO and new ADA criteria for the diagnosis of diabetes mellitus in three ethnic groups in the UK. Diabet Med 1998;15:554-7.

3 Harris MI, Eastman RC, Cowie CC, Flegal KM, Eberhard MS. Comparis of dian US population according to 1997 American Diabetes
Association and 1980-1985 World Health Organization diagnostic criteria. Diabetes Care 1997;20:1859-62.

4 Ramachandran A, Snehalatha C, Latha E, Vijay V. Evaluation of the use of fasting plasma glucose as a new diagnostic criterion for diabetes in Asian Indian population. Diabetes Care 1998;21:666-7.

5 Shaw JE, de Courten MP, Hodge AM, Zimmet PZ. Can fasting glucose ever be adequate to screen for diabetes? Diabetes 1998;47(suppl 1):A150.

\section{A way of identifying all those at risk of long term complications of diabetes is still needed}

EDITOR-We agree with the conclusions of the DECODE Study Group on the diagnostic criteria for diabetes mellitus. ${ }^{1}$ The American Diabetes Association (ADA) should have allowed time for more international discussion before abandoning the oral glucose tolerance test and making fasting plasma glucose concentration the criterion for diagnosis. ${ }^{2}$

The DECODE Study Group showed that only $28 \%$ of subjects classed as diabetic by either ADA or World Health Organisation criteria were thus classed by both methods. In a study of 401 patients with suspected diabetes, we found a higher degree of concordance between the two methods $(68 \%){ }^{3}$ More of our subjects had greater degrees of glucose intolerance, but we found a substantial proportion of discordant findings $(32 \%)$ in both directions; these tended to cancel each other out when the prevalence of diabetes was calculated by using the two methods. In contrast to the DECODE Study Group, we found that the $\mathrm{ADA}$ criteria gave a slightly lower prevalence of diabetes $(41.4 \%)$ in our population than did the WHO criteria $(44.4 \%)$, but this is influenced by the reliability of fasting, which is one of the main disadvantages of the $\mathrm{ADA}$ system.

The ADA recommendations effectively replace impaired glucose tolerance with impaired fasting glucose concentration ( $\geqslant 6.1 \mathrm{mmol} / \mathrm{l}$ and $<7.0 \mathrm{mmol} / \mathrm{l}$ ). However, our study shows that the two categories are not equivalent. ${ }^{3}$ Of 110 subjects classed as having impaired glucose tolerance or impaired fasting glucose concentrations, only $27(25 \%)$ were thus classed by both methods. Indeed, the original work on impaired fasting glucose concentration shows that impaired glucose tolerance in comparison with the fasting concentration is 1.7 times more likely to predict progression to diabetes over 3 years.

In view of the potential reclassification of disease in individual subjects that introducing the ADA system would imply, we believe that further consideration is needed. The best course of action is probably the minor modifications proposed by the WHO to its current criteria. ${ }^{5}$ These entail retaining the oral glucose tolerance test for equivocal cases but lowering the fasting plasma glucose criterion. However, the same problem remains: how to identify as having diabetes those subjects who are at risk of developing the long term complications of diabetes without including those who will not. We still do not know whether measurement of plasma glucose concentration when fasting or after a glucose load, or even some other measure such as haemoglobin $\mathrm{A}_{1 \mathrm{c}}$ concentration, is the best way of doing this.

K Wiener Principal biochemist

Department of Clinical Biochemistry, North

Manchester General Hospital, Manchester M8 5RB

N B Roberts Consultant clinical scientist

Department of Clinical Chemistry, Royal Liverpool University Hospital, Liverpool L7 8XP

1 DECODE Study Group on behalf of the European Diabetes Epidemiology Study Group. Will new diagnostic criteria for diabetes mellitus change phenotype of patients with diabetes? Reanalysis of European epidemiological data $B M J 1998 \cdot 317 \cdot 371-5$. (8 August)

2 Expert Committe on the Diagnosis and Classification of Expert Committee on the Diagnosis and Classification of Diabetes Mellitus. Report. Diabetes Care 1997,20:1183-97.

A $\mathrm{A}_{1 \mathrm{c}}$ and fasting plasma glucose as first-line diagnostic tests for diabetes mellitur

4 Charles MA, Fontbonne A, Thibult N, Warnet J-M, Rosselin GE, Eschwege E. Risk factors for NIDDM in white population: Paris prospective study. Diabetes 1991;40: $796-9$

5 Alberti KGMM, Zimmet PZ for the WHO Consultation. Definition, diagnosis and classification of diabetes mellitus and its complications. I. Diagnosis and classification of diabetes mellitus. Provisional report of a WHO consultation. Diabet Med 1998;15:539-53.

\section{The reanalysis by the DECODE Study Group needs to be reanalysed}

Editor-The report of the American Diabetes Association's (ADA) expert committee on diagnosis and classification of diabetes mellitus was based exclusively on plasma glucose concentration and did not provide the equivalent blood glucose values for venous or capillary whole blood. ${ }^{1}$ This observation is important because a careful analysis of the paper by the DECODE Study Group $^{2}$ comparing the World Health Organisation's recommendations of 1985 with the new ADA criteria shows clearly that the largest positive differences in the prevalence of diabetes in favour of ADA guidelines were observed largely in data based on venous and capillary whole blood glucose (tables 1 and 2). ${ }^{2}$ If these data are excluded, the differences in diabetes prevalence will range from a reduction of $4 \%$ to an increase of $2.7 \%$ instead of $13.2 \%$ as reported. Furthermore, instead of a net increase in the overall prevalence of diabetes with the ADA criteria as the study found, there would be a net decrease as the ADA report predicted. ${ }^{1}$

The investigators did not provide the basis for using a fasting blood glucose value of $6.1 \mathrm{mmol} / 1$ for both venous and capillary whole blood as the equivalent of a plasma glucose concentration of $7.0 \mathrm{mmol} / 1$ in the ADA recommendations. At the same time, for the 2 hour glucose values, $11.1 \mathrm{mmol} / 1$ was used for both capillary whole blood and plasma glucose concentrations. The cut off value of $6.1 \mathrm{mmol} / \mathrm{l}$ for fasting venous and capillary whole blood used for the ADA criteria may have resulted in artificially high estimates of the prevalence of diabetes. Inferences based on these results would therefore be incorrect. Before some of the far reaching conclusions and recommendations made in the study can be valid, it would be best if data based on venous and capillary whole blood are excluded and only those for plasma analysed. Such 
"uncontaminated" data would more truthfully reflect the comparability of the new ADA criteria.

Olufunsho Famuyiwa Consultant physician and endocrinologist

Sabah Hospital, Kuwait

funsofam@kma.org.kw

1 Expert Committee on the Diagnosis and Classification of Diabetes Mellitus. Report. Diabetes Care 1997;20:1183-97.

2 DECODE Study Group on behalf of the European DECODE Study Group on behalf of the European Diabetes Epidemiology Study Group. Will new diagnostic with diabetes? Reanalysis of European epidemiological with diabetes? Reanalysis of Europe
data. $B M J 1998 ; 317: 371-5$. (8 August.)

3 World Health Organisation. Diabetes mellitus: report of a WHO Study Group. Tech Rep Ser 1985; No 727

\section{Authors' reply}

EdiTor-We compared the use of fasting glucose concentrations and the American Diabetes Association (ADA) criteria with the use of 2 hour glucose concentrations and the WHO criteria. Resnick, Harris, and Davies suggest that the WHO criteria should be based on both fasting and 2 hour values. In 1985 the WHO suggested the possibility of measuring only 2 hour glucose concentrations because true fasting cannot be assured, ${ }^{1}$ and this policy has been used in several recent surveys supported and supervised by the WHO (H King, personal communication).

Resnick and Harris say that subjects with fasting plasma glucose concentrations diagnostic of diabetes also have diagnostic 2 hour values. Table 3 of our paper shows that of 1044 people with fasting glucose concentrations diagnostic of diabetes, only 431 $(41 \%)$ had a diagnostic 2 hour value. Isolated high fasting values were most common in obese people and those aged 65 years or under. However, we found the largest discrepancy between the prevalence using $\mathrm{ADA}$ and WHO criteria in elderly Finnish populations.

During the annual meeting of the European Association for the Study of Diabetes we presented mortality data showing that 2 hour glucose values (normal, impaired glucose tolerance, and diabetes) are predictors of excess mortality, but high fasting glucose concentration does not improve the predictive value of a high 2 hour glucose concentration (impaired glucose tolerance or diabetes). We agree with Harris et al that the new category of impaired fasting glucose is not identical with impaired glucose tolerance and that impaired glucose tolerance is relevant for trials aiming at preventing progression to overt diabetes.

Ethnic group is important. To analyse whether the revised diagnostic criteria will have a different impact in different ethnic groups the DECOD-Asia study has been set

Prevalence of diabetes defined by fasting or 2 hour plasma glucose concentrations in all subjects not previously identified as having diabetes

\begin{tabular}{lrcc} 
& \multicolumn{3}{c}{ 2 hour plasma glucose $(\mathbf{m m o l} / \mathbf{l})$} \\
\cline { 2 - 4 } Fasting plasma glucose $(\mathbf{m m o l} / \mathbf{l})$ & $<\mathbf{1 1 . 1}$ & $\geqslant \mathbf{1 1 . 1}$ & \multicolumn{1}{c}{ Total } \\
\hline$<7.0$ & 18695 & 291 & $\mathbf{1 8 9 8 6}$ \\
\hline$\geqslant 7.0$ & 341 & 302 & 643 \\
\hline Total & 19036 & 593 & 19629 \\
\hline
\end{tabular}

up using the same procedures as the DECODE study. We expect to be able to present data on this within 6-9 months.

Wiener and Roberts mention the difference in concordance rates between fasting and 2 hour values in their study and ours. They studied a high risk group admitted with suspected diabetes. These patients are more likely to have advanced disease and thus abnormal fasting and 2 hour glucose concentrations than are our random samples of the population. Their observation of the lack of concordance between impaired fasting glucose concentration and impaired glucose tolerance confirms our (as yet unpublished but submitted) observations. We agree that the oral glucose tolerance test should be retained for clinical diagnosis in subjects with marginally raised fasting plasma glucose concentrations and as the main measurement for epidemiological studies.

ADA recommends using only plasma glucose concentration, ${ }^{3}$ but the WHO does not agree ${ }^{4}$; we used the cut off values for plasma, venous whole blood, and capillary whole blood recommended by the WHO. We reanalysed the data restricting our analysis to centres measuring plasma glucose concentration and excluding subjects with previously diagnosed diabetes (table). The prevalence of diabetes was 3.3\% (643/19 629) with fasting plasma glucose concentration alone, 3.0\% (593/19 629) with 2 hour glucose, and 4.8\% (934/19 629) with both. The degree of reclassification of disease is similar to that in our study.

We still think that further analyses of cross sectional and prospective data are needed before any major change in the diagnostic criteria can be recommended. These studies should focus on predicting mortality, macrovascular complications (fatal and non-fatal), and microvascular complications.

Diabetes should be defined as the glucose concentration at which diagnosis and treatment do more good than harm. A single diabetic complication alone (such as retinopathy in the new criteria) should not be used to define this glucose concentration.

Knut Borch-Johnsen Chief physician Steno Diabetes Centre, Gentofte, Denmark

Jaakko Tuomilehto Professor

Oing Oiao Research fellow

Department of Epidemiology and Health Promotion, National Public Health Institute, Helsinki, Finland

Beverly Balkau Statistician

INSERM U21, Paris, France

World Health Organisation. Diabetes mellitus: report of WHO Study Group. Tech Rep Ser 1985; No 727.
2 Wiener K, Roberts NB. The relative merits of haemoglobin $\mathrm{A}_{1 \mathrm{c}}$ and fasting plasma glucose as first-line diagnostic tests for diabetes in non-pregnant subjects. Diabet Med 1998;15:558-63.

3 Expert Committee on the Diagnosis and Classification of Diabetes Mellitus. Report. Diabetes Care 1997;20:1183-97.

4 Alberti KGMM, Zimmet PZ for the WHO Consultation. Definition, diagnosis and classification of diabetes mellitus and its complications. I. Diagnosis and classification of diabetes mellitus. Provisional report of a WHO Consultation. Diabet Med 1988;15:539-53.

\section{GPs should not connect to NHSnet until it is restructured}

EDitor-The views of de Lusignan and Brown about NHSnet are opposite to those of representative general practitioners because NHSnet has problems that demand its restructuring. The NHS Executive, suppliers, and professions have started this task, and general practitioners should not connect to NHSnet until it is restructured.

The authors wrongly assume that NHSnet is secure enough to send identified patient data across it "in clear" (nonencrypted) and that NHSnet is a preferable medium for handling information to promote evidence based medicine and clinical governance.

In 1994 the BMA established that the threat model for the NHSnet was (and is) wrong. This gave rise to the BMA document Security in Clinical Information Systems ${ }^{2}$ and spawned the debate about NHSnet and personal identifiable clinical data in the NHS. These discussions produced the Caldicott review and its recommendations on the confidentiality of clinical information in the NHS. ${ }^{3}$

The problem is that the NHSnet cannot handle identifiable clinical data safely; it is no better than any other internet provider. Instead, the data have to look after themselves under the assumption that any network carrying them is unsafe. This model is agreed by the NHS Executive, and its encryption programme board has started work to ensure that identifiable clinical data are protected by encryption. It is now axiomatic that no identifiable clinical data should be transmitted down any electronic network, including the NHSnet, without encryption.

Thus practices should not connect clinical systems to external networks on a permanent basis-the risks are too high for the gains. Intermittent connection is best and depends on the business justification. If it is worth while, use NHSnet for nonidentifiable data; if not, don't, or find a preferable competitor. Any internet provider can handle anonymised clinical governance data and evidential information, usually faster and more cheaply than NHSnet. The governance data are (or certainly should be) de-identified, and evidential information is on the web anyway. Again, it is a question of the business justification for the service.

The case for NHSnet is not made for general practices. It is not safe, financially attractive yet, or faster than other internet providers. To its credit, the NHS Executive has recognised these problems and is working with the profession to realign NHSnet 
financially and structurally. When this happens, it may then be safe and sensible for practices to connect to NHSnet.

Grant S-B Kelly Chairman

Information Management Subcommittee, UK

General Practitioners Committee, Chichester, West Sussex PO19 4RH

1 De Lusignan S, Brown A. Internet can be accessed from NHSnet. BMJ 1998;317:1319. (7 November.)

2 British Medical Association. Security of clinical information systems. London: BMA, 1996.

3 Department of Health. Caldicott review of patient-identifiable information in the NHS. London: $\mathrm{DoH}, 1997$.

\section{Prescription of proton pump inhibitors}

\section{Ulcer healing drugs affect gastroscopy results}

EDITOR-Bashford et al report a 10-fold rise in prescriptions for proton pump inhibitors between 1991 and 1995, mainly because of increased unlicensed use for non-ulcer dyspepsia. ${ }^{1}$ Diagnosis of non-ulcer dyspepsia will be increased by the frequent use of ulcer healing drugs before referral for gastroscopy because these drugs reduce diagnostic yield. ${ }^{2}$

We audited 270 dyspeptic patients referred for gastroscopy to determine the ideal time to stop ulcer healing drugs before investigation. In all, $154(57 \%)$ patients had taken ulcer healing drugs in the 3 months before gastroscopy; 77 of these received proton pump inhibitors. When we compared patients treated with ulcer healing drugs with those who had not taken these drugs in the 3 months before gastroscopy, treated subjects had a significantly reduced occurrence of mucosal inflammation at gastroscopy-for example, oesophagitis and peptic ulcer disease. The odds ratio of not having mucosal inflammation when ulcer healing drugs were taken within 2 weeks of gastroscopy was $3.1(95 \%$ confidence interval 1.3 to $7.1, \mathrm{P}<0.01)$. The odds ratio when these drugs were taken 2 to 4 weeks before gastroscopy was 2.0 ( 1.0 to $3.9, \mathrm{P}<0.04)$. Use of ulcer healing drugs more than 4 weeks before the test did not affect diagnostic yield. Patients taking ulcer healing drugs within 1 month of endoscopy were also less likely to test positive for Helicobacter pylori.

We performed a telephone survey of 31 endoscopy units in July 1997. Fourteen (45\%) gave no advice about discontinuing ulcer healing drugs before gastroscopy, and only one recommended stopping a month before the procedure.

In summary, ulcer healing drugs used up to 1 month before gastroscopy reduce both diagnostic yield and detection of $\mathrm{H}$ pylori. ${ }^{3}$ Many endoscopy units do not advise patients to discontinue these drugs. This must exaggerate diagnosis of non-ulcer dyspepsia and will result in repeat prescriptions for patients who might have a curable problem such as duodenal ulcer.

Ian Ross Consultant gastroenterologist ross@newark.cnht.cnhc-tr.trent.nhs.uk

June Edgehill Sister in charge, endoscopy unit Newark Hospital, Newark, Nottinghamshire NG24 4DE
1 Bashford JNR, Norwood J, Chapman SR. Why are patients prescribed proton pump inhibitors? Retrospective analysi of link between morbidity and prescribing in the Genera Practice Research Database. BMJ 1998;317:452-6. (15 August.)

2 Mitchell RMS, Tham TCK, Collins JSA, Watson RGP Differences in diagnostic yield of upper gastrointestinal endoscopy in dyspeptic patients on proton pump inhibitors and $\mathrm{H} 2$ receptor antagonists. Gut (supp 1) $1997 ; 40: \mathrm{A} 60$.

3 Dickey W, Kenny BD, McConnell JB. Effect of proton pump inhibitors on the detection of Helicobacter pylori i gastric biopsies. Aliment Pharmacol Ther 1996:10:289-93.

\section{Indications may be more specific than suggested by GP records}

EDIToR-Bashford et al report the reasons that general practitioners prescribe proton pump inhibitors, using data derived from the General Practice Research Database. ${ }^{1}$ They note that one of the limitations of their study is that there may be imprecision in how diagnoses are recorded and that the diagnosis might change from that which was initially entered. We report data from one centre participating in a postmarketing surveillance study of omeprazole which allow quantification of this potential source of error.

During 1993-4, 42 Oxfordshire practices agreed to participate in the study. In all, 892 patients who were current or recent users of omeprazole gave consent for their medical records to be reviewed. ${ }^{2}$ From these records we determined the reason for prescription of omeprazole and the results of any endoscopies and barium meal investigations; $705(79 \%)$ patients had undergone at least one of these investigations. The diagnoses were coded according to ICD-10 (international classification of diseases, 10th revision). The table shows the reasons for prescribing omeprazole and diagnoses taking into account the results of investigations.

Based on the recorded reason for omeprazole, only $464(52 \%)$ patients were being prescribed the drug for licensed indications - a similar proportion to that observed by Bashford et al. This figure rose to $554(62 \%)$ if results of investigations were taken into account. The principal difference is that $88(26 \%)$ patients with the nonspecific diagnosis of indigestion were subsequently given a more precise diagnosis. However, the commonest reasons for pre-

Reasons for prescription of omeprazole recorded by general practitioner and diagnosis after upper gastrointestinal imaging (barium studies or endoscopy), 1993-4. Values are numbers (percentages) of patients

\begin{tabular}{|c|c|c|c|}
\hline Diagnosis (ICD-10 codes) & Recorded reason & $\begin{array}{l}\text { Diagnosis taking into } \\
\text { account imaging }\end{array}$ & Difference in \% \\
\hline \multicolumn{4}{|l|}{ Licensed indication: } \\
\hline Reflux oesophagitis (k20-k21) & $294(33)$ & $318(36)$ & 3 \\
\hline Peptic ulcer (k25-k27) & $54(6)$ & $88(10)$ & 4 \\
\hline Other diseases of oesophagus (k22) & $61(7)$ & $68(8)$ & 1 \\
\hline Gastritis and duodenitis (k29) & $55(6)$ & $80(9)$ & 3 \\
\hline Subtotal & $464(52)$ & $554(62)$ & 10 \\
\hline \multicolumn{4}{|l|}{ Unlicensed indication: } \\
\hline Indigestion (k30) & $339(38)$ & $251(28)$ & -10 \\
\hline Hiatus hernia $(\mathrm{k} 44)^{*}$ & $52(6)$ & $59(7)$ & 1 \\
\hline Miscellaneous gastrointestinal disease & $32(4)$ & $23(3)$ & -1 \\
\hline Malignant neoplasm of stomach (c16) & $4(0)$ & $4(0)$ & 0 \\
\hline Subtotal & $427(48)$ & $337(38)$ & -10 \\
\hline Total† & $891(100)$ & $891(100)$ & \\
\hline
\end{tabular}

*Using Bashford et al's classification, this became a licensed indication in 1993. †Missing data for one patient. scribing omeprazole remain reflux oesophagitis and indigestion, regardless of whether results of investigations are taken into account. Therefore, it is unlikely that imprecision of recorded diagnoseis will have been responsible for significant bias in Bashford et al's study.

Jonathan Mant Senior lecture

Department of Primary Care and General Practice, Medical School, University of Birmingham,

Edgbaston, Birmingham B15 2TT

J.W.Mant@bham.ac.uk

Michael F G Murphy Director, ICRF General Practice Research Group

Martin P Vessey Professor

Institute of Health Sciences, Headington, Oxford OX3 7LF

post-marketing surveill

Bashford JNR, Norwood J, Chapman SR. Why are patients prescribed proton pump inhibitors? Restrospective analysis of link between morbidity and prescribing in the General Practice Research Database. BMJ 1998;317:452-6. (15 August.)

2 Mant JWF, Jenkinson C, Murphy MFG, Clipsham K, Marshall P, Vessey MP. Use of the short form-36 to detect the influence of upper gastro-intestinal disease on self-reported health status. Quality of Life Research 1998;7:221-6.

\section{Insecurity about progression is an added stress for senior house officers}

EDITOR-In their editorial Firth-Cozens and Moss covered some of the factors causing stress among junior doctors. ${ }^{1}$ However, they did not include what is probably the most important cause of stress among many senior house officers in some of the more popular disciplines-that is, insecurity about progression. Unfortunately, the government did not increase the number of consultant posts and specialist registrar posts when the new deal was introduced. The net effect was that the task forces created hundreds of additional senior house officer posts to cope with the reduction in hours. The effects of this failure to match the greatly enlarged number of senior house officers with future career prospects were worsened when the new specialist registrar programme was introduced. 
At the same time the duration of basic professional training was reduced from three to two years, creating an explosion in the number of senior house officers seeking specialist registrar jobs each year. Once again, the number of consultant posts and specialist registrar posts was not increased simultaneously.

The increase in numbers of senior house officers in surgery has meant that, even if surgical registrars who satisfactorily complete basic surgical training and obtain their FRCS/MRCS/AFRCS spend 4 years as senior house officers, a proportion will still not obtain specialist registrar posts in surgery, such is the current mismatch in numbers.

A straw poll of surgical senior house officers found that this mismatch is the main cause of stress. Unless this mismatch is reduced by an increase in the number of consultant and specialist registrar posts, stress is likely to increase with all the adverse factors described by Firth-Cozens and Moss in their editorial.

Charles S B Galasko Chairman, training board Barry Jackson President

Royal College of Surgeons of England, London WC2A 3PN

1 Firth-Cozens J, Moss F. Hours, sleep, teamwork, and stress BMJ 1998;317:1335-6. (14 November.)

\section{Survey of white coat hypertension}

\section{Definition differs from others}

EDITOR-Muscholl et al reported that patients with white coat hypertension showed evidence of target organ damage as manifested by changes in left ventricular structure and function when compared with normotensive subjects. ${ }^{1}$ Though interesting, their results are misleading.

The conventional method for identifying patients with white coat hypertension is by comparing blood pressure measured by a physician in a clinic with measurements made with 24 hour ambulatory monitors. Although there is no agreement as to the exact criteria, the central concept of white coat hypertension is that it is characterised by high blood pressure only in the medical setting; blood pressure is normal at other times. In Muscholl et al's study, all the blood pressure measurements were made in a medical setting. After at least 30 minutes' rest, blood pressure was measured three times by a technician, and the means of the second and third readings were used as the baseline or "non-physician" blood pressure. These readings were compared with blood pressure measured once by a physician after an echocardiographic examination. Patients were classified as having white coat hypertension when the blood pressure measured by the technician was $<140 / 90 \mathrm{~mm} \mathrm{Hg}$ and that recorded by the physician was $\geqslant 160 / 95 \mathrm{~mm} \mathrm{Hg}$. The authors provide no evidence that the technicians' readings are in any way representative of measurements in a non-medical setting, and previous work has shown that although blood pressure measured in a clinic by a non-physician (in this case a nurse) was substantially lower than the physician's readings, ${ }^{3}$ it is not a reliable way of diagnosing white coat hypertension.

The difference in the procedures used by the technician and the physician is also a problem. The technician measured blood pressure three times before the echocardiographic examination, with the first reading omitted from the analysis, whereas the physician measured it only once, after the echocardiographic examination. This makes meaningful comparison between the two sets of readings difficult.

We do not accept the authors' conclusion, based on their data, that white coat hypertension is not a benign condition, because their method of defining white coat hypertension is so different from other definitions in the medical literature

Kazuomi Kario Visiting fellow

Thomas G Pickering Professor of medicine

Hypertension Center, Department of Medicine,

Cornell University Medical College-The New York Hospital, New York, NY 10021, USA

tpicker@mail.med.cornell.edu

1 Muscholl MW, Hense H-W, Brockel U, Doring A, Riegger GAJ, Schunkert H. Changes in left ventricular structure and function in patients with white cont hypetenion: and function in patients with white coat hypertension: Picks sectional survey. BMJ 1998,917.565-70. (29 August.) Brenner BM. Hypertension: pathology, diagnosis, and manage

3 Veerman DP, Van Montfrans GA. Nurse-measured or ambulatory blood pressure in routine hypertension care. J Hypertension 1993;11:287-92

\section{Authors' reply}

EDITOR-Kario and Pickering draw attention to the appropriate definition of white coat hypertension. In their view, blood pressure measured by a physician should be contrasted to measurements from 24 hour ambulatory monitors. We appreciate the opportunity to reiterate in more detail some points that we already addressed in our discussion.

Firstly, the focus of our study was specifically to investigate the "real" white coat effect in the population, its prevalence, and its impact under different conditions. According to Mancia and Zanchetti, the "real" white coat effect refers to the difference that occurs between a doctor's measurement and a variably defined baseline reference'; however, the procedure suggested by Kario and Pickering identifies what has also been named "isolated office hypertension." This phenomenon does not seem to measure the "real" white coat effect and is probably caused by several other mechanisms.

Secondly, the technicians' blood pressure measurements were a meaningful reference level for determination of the white coat effect. They were obtained under highly standardised conditions and, notably, after an extended resting period in a sitting position. ${ }^{3}$ It should further be noted that the study centre was not located in a hospital and that the technicians' rooms contained no medical appliances. Moreover, our technicians did not wear white coats. There- fore, the setting was by intention a non-medical one. We believe that, under the circumstances of a large population study, this is about the closest one can get to obtaining baseline (resting) blood pressure.

Thirdly, the doctor's first measurements were selected as they reflect best the participants' increases in blood pressure under mild stress, before any attenuation to the measurement situation may occur. Finally, we applied a fairly conservative definition of white coat hypertension by using substantially higher cut-off values for measurements by the physician $(160 / 95 \mathrm{~mm} \mathrm{Hg})$ than by the technician $(140 / 90 \mathrm{~mm} \mathrm{Hg})$. In this way, we sought to increase the specificity of our procedure and reduce the number of false positive white coat hypertensive patients.

We concede to Kario and Pickering that our procedure differed from previously used definitions and that this compromises external comparisons. Nevertheless, our study clearly shows that a tendency to increased blood pressure under mild stress in otherwise normotensive subjects is significantly associated with left ventricular hypertrophy.

Hans W Hense Professor of clinical epidemiology Institut für Epidemiologie und Sozialmedizin, University of Münster, Münster, Germany

Michael Muschol Clinical fellow in cardiology Heribert Schunkert Professor of clinical amd molecular cardiology

Klinik und Poliklinik für Innere Medizin II

University of Regensburg, Regensburg, Germany

1 Mancia G, Zanchetti A. White coat hypertension: misnomers, misconceptions and misunderstandings. What should we do next? J Hypertens 1996;14:1049-52.

2 World Health Organisation. Hypertension control. WHO Tech Ser 1996;862:7-8.

3 Hense HW, Koivisto AM, Kuulasmaa K, Zaborskis A, Kupsc W, Tuomilehto J. Assessment of blood pressure measurement quality in the baseline surveys of the WHO MONICA project. J Hum Hypertens 1995;9:935-46.

\section{Advanced trauma life support prolongs patients' lives until specialist help arrives}

EDitor-At the end of his second paragraph Tice states: "Full training in advanced trauma life support for all accident and emergency doctors may lead to complacency and a reluctance to involve other specialties early." The provider course for advanced trauma life support lays great emphasis on obtaining specialist help early in the management of injured patients (advanced trauma life support course, 6th edition). Trained doctors would be expected to anticipate this need from the history and mechanism of injury, and should life threatening or potentially life threatening injuries become apparent during treatment then specialist help would be summoned immediately if not already present.

Training in advanced trauma life support has never been promoted as an opportunity for teaching skills to specialist levels, but it does provide a vital structure of basic skills which allows the patient's life to be prolonged until specialist help arrives. Additionally, it acts as a common framework from which all staff can work successfully. 
Priority of place should be given to those exposed to the management of seriously injured patients. This should include the third of senior house officers who take up a position in accident and emergency medicine but who have no intention of staying in this specialty. They also need skills in advanced trauma life support to manage patients safely.

John Stoneham Chairman

Advanced Trauma Life Support Steering Group, Royal College of Surgeons of England, London WC2A 3 PN

JRS@hive.demon.co.uk

1 Tice W. Training in advanced trauma life support is unnecessary for all senior house officers in accident and emergency. BMJ 1998;317:603. (29 August.)

\section{Indwelling needles carry greater risks than acupuncture techniques}

EDITOR-A discussion of the adverse effects of acupuncture has led to considerable anxiety among those who practise this treatment. ${ }^{1}$ Many have claimed that serious complications are avoidable and therefore do not occur in countries where acupuncturists are adequately trained. It has also been stated that causality is often inadequately established in case reports. Moreover, it has also been said that doctor-acupuncturists are just as likely to cause complications.

In an attempt to respond to these issues available on Medline, Embase, and the Cochrane Library, for all reports of serious adverse effects resulting from acupuncture and published in 1997, the year not covered by our review. The results are summarised in the table. (A complete list of references is available on the $B M J$ 's website. $\left.{ }^{2}\right)$

Eight adverse effects were reported. The most common was pneumothorax. Five reports originated in the United States, and one each in Japan, Taiwan, and Brazil. One complication was caused by an acupuncturist who was not medically qualified. ${ }^{3}$ No information on qualifications was given in the other cases, but it was implied that treatment was carried out by non-medically trained acupuncturists. The use of indwelling needles seems to carry greater risks than the use of conventional acupuncture techniques. we systematically searched the literature

Acupuncture is not free of risks. All adverse events reported in 1997 would have been avoidable. The absolute number of cases is small, but the degree of underreporting remains unknown.

\section{E Ernst Director}

e.ernst@ex.ac.uk

A R White Research fellow

Department of Complementary Medicine, Schoo of Postgraduate Medicine and Health Sciences,

University of Exeter, Exeter EX2 4NT

1 Ernst E, White A. Acupuncture: safety first. BMJ 1997;314: 1362

2 www.bmj.com/cgi/eletters/314/7091/1362.

3 Vilke GM, Wulfert EA. Case reports of two patients wit pneumothorax following acupuncture. J Emerg Med 1997:15:155-7.

\section{Few GPs tell patients of their diagnosis of Alzheimer's disease}

Editor-Clafferty et al have found that under half of psychiatrists inform patients with Alzheimer's disease of their diagnosis. We recently published a study in which 372 questionnaires were sent to GPs asking about their practice in disclosing the diagnosis of dementia to their patients. ${ }^{2} \mathrm{We}$ received 281 fully completed replies $(76 \%)$. Only 14 general practitioners $(5 \%)$ always told patients of their diagnosis of dementia, with a further 96 (34\%) often doing so. In cases of terminal cancer, 76 (27\%) general practitioners reported that they always told their patients the diagnosis and a further $190(68 \%)$ often did so, reflecting the change in attitude to physicians talking about cancer with their patients.

Only a small proportion of the many people with dementia will be seen by a psychiatrist. General practitioners are in the front line as far as making a diagnosis is concerned, and they need to be involved in the debate about informing patients with Alzheimer's disease of their diagnosis. Clearly, practice has changed with respect to the disclosure of the diagnosis of cancer; we believe that it will do so with the dementias, particularly as more antidementia drugs come on to the market.

The manner in which the diagnosis of dementia should be disclosed is a topic that warrants further debate in itself.

CA Vassilas Consultant psychiatrist

West Suffolk Hospital, Bury St Edmunds, IP33 2QZ

Summary of eight adverse effects of acupuncture reported in $1997^{2}$

\begin{tabular}{|c|c|c|c|}
\hline Condition & How causality established & Outcome & Risk factor identified \\
\hline Auricular perichondritis & Clinical symptoms & Disfigurement & Indwelling needle \\
\hline Bacterial meningitis & $\begin{array}{l}\text { Analysis of cerebrospinal } \\
\text { fluid }\end{array}$ & Full recovery & $\begin{array}{l}\text { Needle inserted through } \\
\text { clothing }\end{array}$ \\
\hline$\overline{\text { Cardiac tamponade }}$ & $\begin{array}{l}\text { Dislodged needle seen in } \\
\text { right ventricle }\end{array}$ & Full recovery after surgery & Indwelling needle \\
\hline Foot drop & $\begin{array}{l}\text { Clinically (nerve conduction } \\
\text { studies) }\end{array}$ & $\begin{array}{l}\text { Physiotherapy with residual } \\
\text { weakness after } 6 \text { years }\end{array}$ & None identified \\
\hline Pneumothorax & Chest $x$ ray & Full recovery & $\begin{array}{c}\text { Elderly patient, chronic } \\
\text { bronchitis }\end{array}$ \\
\hline Pneumothorax & Chest $x$ ray & Full recovery & Cystic fibrosis \\
\hline Pneumothorax & Chest $x$ ray & Full recovery & None identified \\
\hline Pyarthrosis & Analysis of joint fluid & Full recovery & None identified \\
\hline
\end{tabular}

J Donaldson Medical student

St Bartholomew's School of Medicine and Dentistry, London E1 2AD

1 Clafferty RA, Brown KW, McCabe E. Under half of psychiatrists tell patients their diagnosis of Alzheimer's disease. BMJ 1998:317:603. (29 August.)

2 Vassilas CA, Donaldson J. Telling the truth: what do general practitioners say to patients with dementia or terminal cancer? Br J Gen Pract 1998:48:1081-2.

\section{Cervical screening for women with learning disability} Editorial by Aspray et al

\section{Numbers screened can be optimised by using a focused initiative}

EDITOR-Pearson et al were concerned to find that only a quarter of eligible women with learning disability in Exeter and District Community Health Services NHS Trust had undergone cervical screening in the previous five years, compared with $82 \%$ of the rest of the eligible population. ${ }^{1}$ In 1997, Horizon NHS Trust, Hertfordshire Health Promotion, and the Women's Nationwide Cancer Control Campaign cooperated over an intensive programme to screen the 126 eligible women in the learning disability hospital. As previous experience had shown the importance of securing carers' support, staff and some patients participated in educational sessions. The members of the trust's sex education team provided advice and educational models and made themselves available in case the process should provoke disturbing memories, as might happen in the case of previous sexual abuse.

Given the screening-as opposed to curative-nature of the procedure, no resident was tested who withheld consent (whether valid or not) or failed to cooperate passively. Despite the procedure being a routine public health measure, relatives were, as a matter of good practice, informed unless the patient indicated on direct questioning that they should not be.

Of the 128 eligible women, 40 were withdrawn because they were considered to be behaviourally or physically unable to participate. Of the remainder, 25 proved to be virgins or behaviourally unsuitable or refused consent; 18 did not cooperate. Forty five $(35 \%)$ underwent cervical screening; 39 smears gave negative results, five were inadequate, and one showed an abnormality. The difficulties encountered because of the high proportion of psychiatric cases and cases of challenging behaviour and of physical disability in the trust's population compared with people living in the community may to an extent be offset by the logistically easier task of arranging the resource intensive programme in a relatively small organisation.

The lessons learnt from this programme were that the numbers screened can be optimised by a focused initiative that includes education of carers to support the programme and the patients; the procedure should be carried out only by women staff to avoid embarrassment; it is not possible to predict who has had sexual experience; and 
the doctor taking the smears must be skilled and flexible enough to be able to take them in any position offered.

Peter Hall Doctor, physical health care needs Horizon NHS Trust, Radlett, Hertfordshire WD7 9HQ

Elizabeth Ward Family planning officer Women's Nationwide Cancer Control Campaign, London EC2A 3AR

1 Pearson V, Davis C, Ruoff C, Dyer J. One quarter of women with learning disability in Exeter have cervical screening. BMJ 1998;316:1979. (27 June.)

\section{Concerted effort is needed to ensure these women use preventive services}

EDITOR-A recent review of cervical and breast screening in Brent and Harrow Health Authority showed similarly low levels of cervical screening among women with learning difficulties $(19 \%)$ to that reported from Exeter (24\%). ${ }^{1}$ Altogether 336 women aged 20-64 were identified from Brent and Harrow's learning disability registers, and their screening records were reviewed. Only $64(19 \%)$ of the 336 women had had a cervical smear within the past 5 years, $13(4 \%)$ had had a total hysterectomy, and the remaining $259(77 \%)$ did not have any screening records. Breast screening had been performed in 32 (43\%) of 73 women (figure)

We sent 259 questionnaires to the 133 general practitioners of all the women without a cervical screening record; 87 general practitiones returned 166 questionnaires $(64 \%)$. For most women, more than one reason was given. An assumption that women were sexually inactive was stated in 121 questionnaires and was the commonest reason why general practitioners failed to perform a smear test, although no real evidence exists to confirm this assumption. Difficulties in performing the examination were stated for 56 women, because of their sexual inactivity, physical disability, or insufficient understanding of the examination. In 39 questionnaires the general practitioners expressed concern that examination could not be performed because consent could not be obtained from the women, their families, or their carers. Twelve women were not screened because they had left the practice and could not be traced or

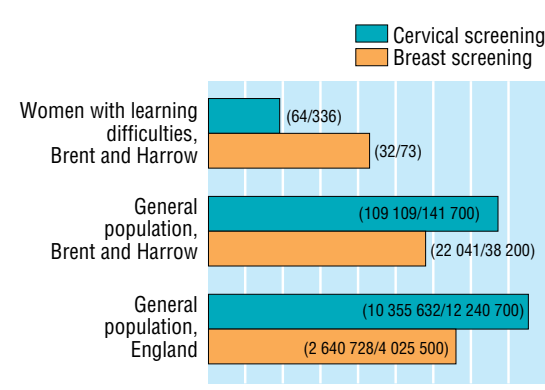

Coverage rates for cervical and breast screening in women with learning disability in comparison with general poulation. Source: Department of Health's statistical bulletins for breast (1996-7, 1998 (10)) and cervical (1996-7, 1997 (27)) screening programme in England did not respond to the invitation letters. Screening was not offered to six women.

People with learning disabilities have much greater health needs then the general population but use preventive services less than is expected. ${ }^{23}$ In addition, general practitioners' role as providers of health promotion and routine screening for these patients is not generally accepted. ${ }^{4}$ The review identified several obstacles to the successful implementation of routine screening among women with learning disabilities. Only concerted effort between healthcare professionals, this particular group of people, and their carers will result in the delivery of good quality health services for those who are most in need.

Tamara Djuretic Specialist registrar Tish Laing-Morton Consultant in public health medicine

Margaret Guy Consultant in public health medicine Mike Gill Director of public health

Brent and Harrow Health Authority, Harrow, Middlesex HA1 3EX

1 Pearson V, Davis C, Ruoff C, Dyer J. Only one quarter of women with learning disability in Exeter have cervical screening. BMJ 1998;316:1979. (27 June)

2 Lindsey M. Signposts for success in commissioning and providing health services for people with learning disabilities. Leeds: NHS Executive, 1998 .

3 Piachaud J, Rohde J. Screening for breast cancer is necessary in patients with learning disability. $B M J$ sary in patients with
1998;316:1979-80. (27 June.)

4 Keer M, Dunstan F, Thapar A. Attitudes of general practitioners to caring for people with learning disability. $\mathrm{Br} J$ Gen Pract 1996:46:92-4.

\section{Sefton has multidisciplinary group to promote sexual health care for these women}

EDITOR-Southport and Formby NHS Trust shares the experience of Exeter and District Community Health Services NHS Trust with regard to cervical screening and women with learning disability. ${ }^{1}$ In 1995 a survey of 50 women with learning disability in one locality in Sefton, Merseyside, was performed to assess accessibility of primary healthcare services and to identify the nature of the problems with access as experienced by service users. This survey showed that $43(86 \%)$ of 50 women with learning disability who were eligible for cervical screening had never had a smear test.

To promote sexual health care and to address this and similar issues, Sefton now has a multidisciplinary group, comprising representatives from social services, health, education, voluntary services, carers' groups, and people with learning disability. Recently a local general practice has requested help from the group regarding the best way to ensure that women with learning disability (of whom it has a relatively high number) receive the same opportunity to access the cervical screening programme as women without learning disability. Despite efforts by the practice nurse to target these women, uptake of cytological screening remained disappointingly low. In response to this a research study is planned to investigate the barriers that prevent women with learning disability from accessing cervical screening and to identify features of good practice in the delivery of preventive health care to this vulnerable group. The training needs of the primary health team will subsequently be assessed.

The Department of Health has recommended that "people with learning disability should be helped to overcome any difficulties in using the full range of general health services." ${ }^{2}$ The results of our research may identify the most effective way of achieving this for cervical cytology.

Jane Whitmore Consultant in family planning and reproductive health

Southport and Formby NHS Trust, Southport PR9 0LT

1 Pearson V, Davis C, Ruoff C, Dyer J. Only one quarter of women with learning disability in Exeter have cervical screening. BMJ 1998:316:1979. (27 June.)

2 Lindsey M. Signposts for success in commissioning and providing health services for people with learning disabilities. Leeds: NHS Executive, 1998.

\section{Central regulating body is needed for ATLS courses}

EDITOR-Advance trauma life support courses have now become an integral part of basic training for most doctors and are an essential requirement for higher surgical training. These courses have strict guidelines like other courses and provide excellent training for management of acutely traumatised patients.

The courses are conducted at various centres by each region throughout the United Kingdom. Each of them has different methods for selecting candidates. Broadly, they are of two types. One system registers all candidates in the United Kingdom and puts them on a waiting list, whereas the other registers only regional candidates. In the regional system, if candidates move outside the region, which is common in stand alone posts, they lose the place and have to start from scratch in their new region. In the first system, a candidate from the same region as the centre usually gets preference over other candidates.

The selection systems have resulted in most candidates applying for as many courses as possible so that they can get a place. This has resulted in long waiting lists. For example, in Manchester it is 3-4 years and in York it is 2-3 years. These waiting list figures are not accurate because the lists share many candidates.

On the other side of the coin, sometimes a doctor gets offered more than one place. This causes difficulty for conducting bodies, which have to find someone at short notice. Conducting bodies also have to handle constant inquiries from candidates about getting a place.

Can we have a central regulating body to solve these genuine problems of doctors and conducting bodies? This could relieve the stress and provide justice and peace of mind for everyone.

Sanjeev R Patil Senior house officer in orthopaedics South Manchester University Hospitals, Manchester M23 9LT 


\section{Contact allergy is unlikely to mimic basal cell carcinoma}

EDITOR-Hogg reported a textbook example of a basal cell carcinoma in which biopsy was non-diagnostic. ${ }^{1}$ The lesion apparently resolved after potent topical steroids were given based on a diagnosis of "sensitivity to PPD, a component of hair dye."

We regularly deal with both periorbital tumours and allergic contact dermatitis and would advise caution about accepting the conclusions of this case at face value. Firstly, both the clinical appearances and the possibility of a false negative biopsy result (sampling error) make us suspicious of the claim that the lesion was completely benign. It is wise to repeat a biopsy when the result is not compatible with the clinical picture. Secondly, apparent resolution of the lesion after topical steroids have been given does not exclude the diagnosis of basal cell carcinoma, which is known to wax and wane.

Thirdly, contact allergy to PPD in hair dye typically results in eczematous changes at the scalp margin and periorbital skin bilaterally. It does not usually cause a solitary skin lesion. In this case the contact allergy to PPD found by patch testing is likely to be coincidental. Positive patch test results should be considered relevant only if they are compatible with the clinical picture.

We hope that this case will not result in any reduction of clinical vigilance. Significant delay in the diagnosis of skin cancer in this anatomical site may result in the progressive destruction of tissues, which complicates both complete removal and reconstruction.

Fiona M Chapman Visiting oculoplastic fellow A3465694@infotrade.co.uk

Brian Leatherbarrow Consultant ophthalmologist, oculoplastic and orbital surgeon

Manchester Royal Eye Hospital, Manchester M13 9WH

Michael H Beck Consultant dermatologist Contact Dermatitis Investigation Unit, Dermatology Centre, Hope Hospital, Manchester M6 8HD

Nicholas R Telfer Consultant dermatologist Mohs Micrographic Surgery Unit, Dermatology Centre, Hope Hospital

1 Hogg RP. Minerva. BMJ 1998;317:548. (22 August.)

\section{Diagnosis of Creutzfeldt-Jakob disease}

Routine tonsil biopsy for diagnosis of new variant Creutzfeldt-Jakob disease is not justified

EDITOR-Collinge et al recommend that tonsil biopsy be considered in all those in whom new variant Creutzfeldt-Jakob disease is suspected. ${ }^{1}$ Though the detection of protease resistant prion protein in tonsillar tissue from a young person with a rapidly progressive dementia may have a high specificity for this diagnosis, there are no published data on sensitivity, specificity, or safety; the procedure carries the risk of haemorrhage and infection as well as the risks associated with anaesthesia. Some patients clinically suspected of having new variant Creutzfeldt-Jakob disease, and therefore potential candidates for tonsil biopsy, have subsequently recovered. ${ }^{2}$ Further information is obviously required, and we concur with the recommendation of a recent $\mathrm{WHO}$ consultation that this should come from postmortem studies.

Brain biopsy has been carried out in 9 of the 27 cases of new variant CreutzfeldtJakob disease in the United Kingdom. This procedure has risks but, in contrast to tonsillar biopsy, enables potentially treatable neurological disorders to be identified. New variant Creutzfeldt-Jakob disease is confirmed in about 1 in 7 cases, ${ }^{2}$ and routine tonsillar biopsy in the population of suspected cases would lead to a high proportion of negative results. A negative result on tonsillar biopsy does not preclude the necessity to proceed to brain biopsy in selected cases. There is clearly a need for a non-invasive diagnostic test for new variant Creutzfeldt-Jakob disease, and preliminary investigation indicates that the presence of posterior thalamic high signal on brain magnetic resonance imaging may be diagnostically useful. ${ }^{4}$

The accepted clinical diagnostic criteria for sporadic Creutzfeldt-Jakob disease have depended on electroencephalography, and an alternative paraclinical criterion would be useful. Cerebrospinal fluid 14-3-3 protein has proved to be a remarkably sensitive and specific marker for sporadic CreutzfeldtJakob disease when used appropriately. Protease resistant prion protein has not been detected in palatine tonsillar tissue obtained at necropsy from the small number of patients with sporadic Creutzfeldt-Jakob disease studied to date (unpublished data). Unless necropsy studies yield positive results, the clinical use of tonsil biopsy in sporadic Creutzfeldt-Jakob disease is not justified.

M Zeidler Specialist registrar

R Knight Consultant neurologist

G Stewart Specialist registrar

J W Ironside Consultant neuropathologist

R G Will Director

CJD Surveillance Unit, Western General Hospital, Edinburgh EH4 2XU

A J E Green Clinical scientist

Department of Neuroimmunology, National

Hospital for Neurology and Neurosurgery, London WC1N 3BG

M Pocchiari Director of research

Laboratory of Virology, Instituto Superiore di

Sanità, Rome, Italy

1 Collinge J, Rossor MN, Thomas D, Frosh A, Tolley N. Tonsil biopsy helps diagnose new variant Creutzfeldt-Jakob disease. BMJ 1998:317:472. (15 August.)

2 Will RG, Knight RSG, Zeidler M, Stewart G, Ironside JW, Cousens SN, Smith PG. Reporting of suspect new variant

Creutzfeldt-Jakob disease. Lancet 1997;349:847.
3 World Health Organisation. Report of a WHO Consultation 3 World Health Organisation. Report of a WHO Consultation
on the global surveillance, diagnosis and therapy of human transmissible spongiform encephalopathies. Geneva: WHO, 1998.

4 Sellar RJ, Will RG, Zeidler M. MR Imaging of new varian Creutzfeldt-Jakob disease: the pulvinar sign. Neuroradiology 1997;39(suppl 1):S53.

5 Kawashima T, Furukawa H, Doh-ura K, Iwaki T. Diagnosis of new variant Creutzfeldt-Jakob disease by tonsil biopsy. Lancet 1997;350:68-9.

\section{Subtypes of $\mathbf{S 1 0 0}$ proteins must be} identified

EDITOR-It is absolutely necessary to determine which $\mathrm{S} 100$ protein is measured in studies, such as that by Otto et al, ${ }^{1}$ that use these proteins to diagnose Creutzfeldt-Jakob disease. Eighteen S100 proteins are now known, and they have a divergent pattern of cell specific and tissue specific expression, distinct subcellular localisations, different affinities for $\mathrm{Ca}^{++}$but also for $\mathrm{Zn}^{++}$and $\mathrm{Cu}^{++}$, and distinct intracellular and extracellular functions. ${ }^{23}$ Several S100 proteins are abundant in the brain-S100B and S100A6, for example, are expressed there in different subpopulations of neurones and glial cells. ${ }^{4}$ Therefore, the subtype of S100 protein must be identified if the diagnosis of Creutzfeldt-Jakob disease is to be valid.

Furthermore, commercially available antibodies used in most studies are directed against a mixture of bovine brain S100 proteins; depending on the manufacturer, these react mostly against $\mathrm{S} 100 \mathrm{~B}$ but also against other S100 proteins. ${ }^{5}$

The studies by Otto et al probably determined concentrations of S100B. S100B, however, is closely associated with Alzheimer's disease. In addition, blood concentrations of S100B are of prognostic value for malignant melanoma and are a measure for brain damage after cardiac arrest.

All these complications could be circumvented by developing more specific and sensitive tests for measuring the individual brain S100 proteins in neurodegenerative disorders. Several well defined antibodies to S100 are now available.

\section{W Heizmann Professor}

Department of Pediatrics, University of

Zurich,CH-8032 Zurich, Switzerland

heizmann@kispi.unizh.ch

1 Otto M, Wiltfang J, Schütz E, Zerr I, Otto A, Pfahlberg A, et al. Diagnosis of Creutzfeld-Jakob disease by measurement of S100 protein in serum: prospective case-control study. BMJ 1998;316:577-82.

2 Schäfer BW, Heizmann CW. The S100 family of EF-hand calcium-binding proteins: functions and pathology. TIBS 1996;21:134-40.

3 Heizmann CW, Cox JA. New perspectives on S100 proteins: a multi-functional $\mathrm{Ca}^{2+}-, \mathrm{Zn}^{2+}-$ and $\mathrm{Cu}^{2+}$ binding protein family. Biometals 1998;11:383-97.

4 Yamashita N, Ilg EC, Schäfer BW, Heizmann CW, Kosaka T. Distribution of a specific $\mathrm{Ca}^{2+}$ binding protein of the S100 protein family, S100A6 (calcyclin), in subpopulations of neurons and glial cells of the adult rat nervous system. of Comp Neurol 1999;404:235-57.

5 Ilg EC, Schäfer BW, Heizmann CW Expression pattern of

S100 calcium-binding proteins in human tumors. Int J Cancer 1998:68:325-32.

\section{Cholesterol: how low is low enough?}

Effect of a given concentration depends on several factors

EDITOR-In his editorial Rosengren considers that reaching target cholesterol concentrations may be better than relative reductions. ${ }^{1}$ He stated that "in observational studies a prolonged difference in usual serum cholesterol value of $0.06 \mathrm{mmol} / \mathrm{l}$ is associated with an almost 30\% reduction in risk of coronary disease."

No one would question the need for reducing serum cholesterol concentration in 
large proportions of adults in Western populations. However, the subject of cholesterol concentration and its pathological importance is complex.

Known risk factors for coronary heart disease, of which serum cholesterol concentration is one, explain only half of the variance in the occurrence of the disease. ${ }^{2}$ There are also numerous contextual problems. For example, in the Sheffield risk table, cholesterol reduction may be called for at $5.5 \mathrm{mmol} / \mathrm{l}$ in those at high risk, whereas intervention may not be needed until $9.0 \mathrm{mmol} / \mathrm{l}$ in those at low risk. ${ }^{3}$ The experience of coronary heart disease also differs between Belfast and Toulouse. Although mean cholesterol concentrations in the two cities are similar, 6.19 and $5.94 \mathrm{mmol} / \mathrm{l}$, mortality from the disease is 3-4 times higher in Belfast than in Toulouse. ${ }^{4}$

Perplexities are also common in populations in developing countries, as in South Africa. ${ }^{5}$ In early studies mean cholesterol concentration in middle aged African men was about $4.0 \mathrm{mmol} / \mathrm{l}$, with observations at necropsy showing a low rate of atherosclerotic lesions of the aorta and a negligible number of deaths from the disease. Currently, in Soweto (3-4 million inhabitants) the mean cholesterol concentration is about $5 \mathrm{mmol} / \mathrm{l}$. Yet coronary heart disease remains uncommon, being responsible for less than $0.5 \%$ of total deaths. Similar reports of the disease's comparative rarity have emanated from big cities in other countries in Africa. In comparison, in the seven countries study the same mean serum concentration of cholesterol (about $5.15 \mathrm{mmol} / \mathrm{l})$ prevails in Mediterranean countries, but coronary heart disease is responsible for $4.7 \%$ of total deaths.

An additional complicating factor is the wide range of cholesterol concentrations in a community. In African village schoolchildren, almost all of the same poor socioeconomic state and accustomed to the same low atherogenic diet, cholesterol concentration varied from 2.5 to $4.2 \mathrm{mmol} / \mathrm{l}$.

To reiterate, although cholesterol concentration has a role in coronary heart disease, a given concentration has widely different connotations for ill, being affected by familiality, ethnic group, sex, and environmental factors.

\section{A R P Walker Head}

Human Biochemistry Research Unit, Department of Tropical Diseases, School of Pathology of the University of the Witwatersrand and the South African Institute for Medical Research,

Johannesburg, South Africa

alexw@mail.saimr.wits.ac.za

1 Rosengren A. Cholesterol: how low is low enough? BMJ 1998;317:425-6. (15 August)

2 Leeder S, Gliksman M. Prospects for preventing heart disease. BMJ 1990;301:1004-5.

3 Haq IU, Jackson PR, Yeo WW, Ramsay LE. Sheffield risk and treatment table for cholesterol lowering for primary prevention of coronary heart disease. Lance $1995 ; 346: 1467-71$

4 Evans AE, Ruidavets J-B, McCrum EE, Cambou J-P, McClean R, Douste-Blazy P, et al. Autres pays, autres coeurs? Dietary patterns, risk factors and ischaemic heart disease in Belfast and Toulouse. OJ Med 1995;88:469-77.

5 Walker ARP, Sareli P. Coronary heart disease: outlook for Africa. JR Soc Med 1997;90:937-8.
Doctors have been slow in getting evidence on lowering cholesterol into practice

EDITOR-Rosengren rightly states that treatment of patients with established coronary heart disease is mandatory. ${ }^{1}$ Prolonged statin treatment reduces events by more than 30\%: the seven year results of the Scandinavian simvastatin survival study show a $45 \%$ reduction (T Pedersen, drugs and lipid metabolism symposium, Florence, June 1998). However, the suggested target concentration for low density lipoprotein cholesterol of $2.6 \mathrm{mmol} / \mathrm{l}$ differs from the recommendation of the Standing Medical Advisory Committee of $<3.2 \mathrm{mmol} / \mathrm{l}$ after infarction. There is little evidence for which target is correct, except in patients with coronary bypass grafts $(<2.6 \mathrm{mmol} / \mathrm{l})$.

The first infarction is fatal for many patients. One study in both sexes showed a $34 \%$ reduction in events starting at a risk of $1.2 \%$ per year, ${ }^{2}$ and the west of Scotland coronary prevention study in men showed a $33 \%$ reduction in mortality at a risk of $1.5 \%$ per year. ${ }^{3}$ Yet, Ramsay et al still suggest using a threshold of 3\% per year rather than the internationally recognised $2 \%$ per year. ${ }^{4}$ The Sheffield tables are an attempt to ration statin treatment despite the evidence no because of it.

Patients with familial hyperlipidaemias are common (1 in 250) and have a large excess mortality and morbidity at an early age when calculated risk does not approach 1\% per year. The Sheffield tables fail to define patients with a familial hyperlipidaemia accurately as physical signs are often absent and the penetrance of coronary heart disease may be poor. In the case of a euthyroid patient with a total cholesterol concentration of $10 \mathrm{mmol} / 1$ (after exclusion of renal disease, which carries a fourfold increased risk of coronary disease) the chances of this being due to non-familial causes are $<1$ in 10000 .

We agree with Ramsay et al that general practitioners ought to decide. Yet it seems strange that opinion from lipid specialists on the utility of the Sheffield tables is not worthy of note by others concerned with the production of guidelines. The tables cited by McLeod and Armitage or the European societies allow general practitioners to calculate an approximate risk and then decide in the light of international recommendations. ${ }^{5}$ In contrast, a prescriptive approach is adopted in the Sheffield tables. Guidelines excepted, it is a depressing fact that most patients with coronary artery disease are still not receiving statin treatment four years after the publication of the Scandinavian simvastatin survival study and that most of those treated are treated inadequately.

A S Wierzbicki Senior lecturer in chemical pathology King's College, St Thomas's Hospital Campus, London SE1 7EH p.lumb@umds.ac.uk

T M Reynolds Professor

Department of Chemical Pathology, Burton

Hospital, Burton on Trent DE13 0RB

1 Rosengren A. Cholesterol: how low is low enough? $B M /$ 1998;317:425-6. (15 August.)
2 Downs JR, Clearfield M, Weis S, Whitney E, Shapiro DR, Beere PA, et al. Primary prevention of acute coronary events with lovastatin in men and women with average cholesterol levels. Results of the AFCAPS/TexCAPS. JAMA 1998;279:1615-22.

3 Shepherd J, Cobbe SM, Ford I, Isles CG, Lorimer AR, MacFarlane PW, et al. Prevention of coronary heart disease with pravastatin in men with hypercholesterolemia. $N$ Engl J Med 1995;333:1301-7.

4 Ramsay LE, Wallis EJ, Haq IU, Williamson R, Yeo WW, Jackson PR. Use of statins. BMJ 1998;317:473-4. (15 August) 5 McLeod AJ, Armitage M. Use of statins. BMJ 1998:317:474. (15 August.)

\section{Women's risk of dying of heart disease is always greater than their risk of dying of breast \\ cancer}

EDITOR-Bunker et al put in perspective the risks of women developing and dying of breast cancer. ${ }^{1}$ It may, however, be useful to clarify the distinction between the cumulative risk they report-the risk of a woman developing breast cancer before a certain age- and the risk of her developing it in the remainder of her life after a certain age. It is the latter that leads to the oft quoted figure of 1 in 12. In fact, this figure applies only to a young woman (say, aged 30 ). The remaining lifetime risk then decreases as she survives to older ages (table).

Risk of woman developing or dying of breast cancer or dying of heart disease (International Classification of Diseases codes 390-429) during her remaining life*

\begin{tabular}{lccc}
$\begin{array}{l}\text { Age } \\
\text { (years) }\end{array}$ & $\begin{array}{c}\text { Risk of } \\
\text { developing } \\
\text { breast cancer }\end{array}$ & $\begin{array}{c}\text { Risk of dying } \\
\text { of breast } \\
\text { cancer }\end{array}$ & $\begin{array}{c}\text { Risk of dying } \\
\text { of heart } \\
\text { disease }\end{array}$ \\
\hline 30 & $1 / 12$ & $1 / 24$ & $1 / 3.4$ \\
\hline 40 & $1 / 12$ & $1 / 25$ & $1 / 3.4$ \\
\hline 50 & $1 / 14$ & $1 / 26$ & $1 / 3.4$ \\
\hline 60 & $1 / 18$ & $1 / 30$ & $1 / 3.3$ \\
\hline 70 & $1 / 29$ & $1 / 37$ & $1 / 3.2$ \\
\hline 80 & $1 / 57$ & $1 / 48$ & $1 / 3.2$ \\
\hline
\end{tabular}

*Based on data from Office for National Statistics. ${ }^{23}$

By the time a woman has reached the age of 70 her chance of developing breast cancer during her remaining life is reduced to 1 in 29. Similarly, a woman's risk of dying of breast cancer during her remaining life decreases as her age increases. This is in contrast to her risk of dying of heart disease (International Classification of Diseases codes 390-429) during her remaining life, which remains at about 1 in 3.3 throughout life: increasing age brings a much more rapid increase in mortality from heart disease than from breast cancer, as Bunker et al show.

John Haybittle Visiting worke

MRC Clinical Trials Unit, Cancer Division, Cambridge CB2 2BW

1 Bunker JP, Houghton J, Baum M. Putting the risk of breas cancer in perspective BMJ 1998;317:1307-9. (7 November) 2 Office for National Statistics. 1989 Cancer statistics registrations. London: Stationery Office, 1995. (Series MB 1 No 29. Office for National Statistics. 1995 M. (Series $\left.\mathrm{MB} 1, \mathrm{No}_{2} 2.\right)$ London: Stational Statistics. 1995 Mortality statistics: causc

\section{Rapid responses $\quad$ eBM \\ Rapid responses submitted directly to our website are available on www.bmj.com}

